\title{
Synergism of Rhizobium and Rhizobacteria on Growth, Symbiotic Parameters, Soil Quality and Grain Yield in Summer Mungbean (Vigna radiata L. Wilczek)
}

\author{
Premlata Kumari $^{{ }^{*}}$, Poonam Sharma ${ }^{2}$ and Sunita Sharma ${ }^{2}$ \\ ${ }^{1}$ Department of Microbiology, Punjab Agricultural University, Ludhiana, Punjab, India \\ ${ }^{2}$ Department of Plant Breeding and Genetics, Punjab Agricultural University, \\ Ludhiana, Punjab, India \\ *Corresponding author
}

\section{A B S T R A C T}

\section{Keywords}

Summer mungbean, Rhizobium,

Rhizobacteria, Consortium

Article Info

Accepted:

05 February 2020

Available Online:

10 March 2020
The present investigation was studied to evaluate the synergistic effect of Rhizobium and rhizobacteria consortium for improving growth, symbiotic efficiency, soil quality and yield in summer mungbean under field conditions during summer season 2015. Mungbean seeds of two varieties (SML668 and SML832) were inoculated with Rhizobium (M1, LSMR1 and LSMR2) singly and in combination with rhizobacteria (LSRB1, LSRB2 and LSRB3). Significantly high dry weight of shoot (4.22 and $\left.5.29 \mathrm{~g} \mathrm{plant}^{-1}\right)$ dry weight of root $(0.411$ and $\left.0.604 \mathrm{~g} \mathrm{plant}^{-1}\right)$ total nitrogen $(1.59$ and $1.52 \%)$ and phosphorus content $(0.109$ and $0.129 \%$ ) of shoot were recorded with consortium of native Rhizobium sp. (LSMR1) and rhizobacteria (LSRB3) in SML668 and SML832 varieties, respectively as compared to Rhizobium sp. alone as well as un-inoculated control. On the basis of overall mean, symbiotic and soil quality parameters were significantly high viz. dry weight of nodules (105.3 mg), leghaemoglobin content $(2.61 \mathrm{mg} / \mathrm{g}$ of nodules), nitrate reductase activity of nodules $\left(13.86 \mu \mathrm{mNO}^{-2} / \mathrm{hr} / \mathrm{g}\right.$ of fresh nodules) and dehydrogenase activity (200 $\mu \mathrm{g}$ $\mathrm{TPF} / \mathrm{g} / \mathrm{soil} / \mathrm{hr}$ ) with LSMR1+LSRB3 treatment as compared to Rhizobium sp. alone as well as un-inoculated control. On an average, consortium of LSMR1+LSRB3 significantly improved the grain yield by $5.7 \%$ over Rhizobium sp. (LSMR1) and 9.2\% over uninoculated control. Therefore present studies conclude that consortium of native Rhizobium sp. and rhizobacteria can be developed as a single delivery system biofertilizer for improving summer mungbean productivity.

\section{Introduction}

Mungbean (Vigna radiata L. Wilczek) is an important source of protein (26\%) for human diets (Keatinge et al., 2011). Mungbean contains $51 \%$ carbohydrate, $26 \%$ protein, $10 \%$ moisture, $4 \%$ minerals and $3 \%$ vitamins
(Afzal et al., 2008). It increases soil fertility due to nitrogen fixing symbiotic rhizobia in root nodules thus adding large amounts of nitrogen to the soil after harvesting (Hosseini, 2008). It enriches the soil and breaks the soil fatigue caused by cereal-cereal rotations. Rhizobium is an excellent example of soil 
bacteria engaged in symbiotic relationship with leguminous plants. They obtain their nutrients from the legume plants and produce nitrogen fixing root nodules through Biological Nitrogen Fixation (Datta et al., 2015) and Rhizobia are known to fix nitrogen $50-100 \mathrm{~kg} / \mathrm{ha}$ in association with legumes only (Venkatashwarlu, 2008). Rhizobium inoculation can be demonstrated in summer mungbean as sustainable environment friendly agro-technological practice. Symbiotic effectiveness of rhizobial inoculants can be improved by co-inoculation with suitable nonrhizobial plant growth promoting bacteria (PGPB) (Lazdunski et al., 2004). Various genera of bacteria, Pseudomonas, Enterobacter, Bacillus, Klebsiella, Burkholderia, Azospirillum, Serratia and Azotobacter, Arthobacter, Hydrogenophaga etc cause a pronounced effect on plant growth and are termed as plant growth promoting rhizobacteria (PGPR) (Verma et al., 2013). The PGPR may (i) promote the plant growth either by using their own metabolism (solubilising phosphates, producing hormones or fixing nitrogen) or directly affecting the plant metabolism (increasing the uptake of water and minerals), enhancing root development, increasing the enzymatic activity of the plant or "helping" other beneficial microorganisms to enhance their action on the plants; (ii) or may promote the plant growth by suppressing plant pathogens. These abilities are of great agriculture importance in terms of improving soil fertility and crop yield, thus reducing the negative impact of chemical fertilizers on the environment and for development of ecofriendly sustainable agriculture (PérezMontano et al., 2014; Gupta et al., 2015). Synergistic effects of RhizobiumPseudomonas co-inoculations have been reported at the level of different symbiotic and plant growth parameters and under different growth conditions (Yadav and verma, 2014). Co-inoculation also improved the nutrient balance and increased the phosphorus and protein concentration in grain of mungbean (Ahamd et al., 2014). Similarly Coinoculation studies with PGPR and Rhizobium/Bradyrhizobium/Mesorhizobium species have shown to increase root and shoot weight, plant vigor, nitrogen fixation and grain yield in various legumes (Valverde et al., 2006; Yadegari et al., 2008; Verma et al., 2012). Co-inoculation of rhizobia with PGPR is therefore important for improving $\mathrm{N}$ and $\mathrm{P}$ availability in sustainable agriculture production systems (Samavat et al., 2012).

Therefore, present study was carried out with the objectives to assess synergistic effect of plant growth promoting consortium of potential native PGPR with Rhizobium sp. for growth, symbiotic efficiency, soil quality and yield in summer mungbean.

\section{Materials and Methods}

\section{Procurement of Bacterial cultures}

Potential native isolates of Rhizobium (M1, LSMR1 and LSMR2) and rhizobacteria (LSRB1, LSRB2 and LSRB3) were obtained from the Pulses section, Department of Plant Breeding and Genetics, Punjab Agricultural University, Ludhiana, Punjab, India. Pure cultures of Rhizobium and rhizobacteria were maintained on Yeast Extract Manitol Agar (YEMA) and Nutrient Agar (NA) medium respectively, and further sub-cultured once a month throughout the period of investigation and stored at $4^{0} \mathrm{C}$ in refrigerator.

\section{Evaluation of Rhizobium and rhizobacteria for growth, symbiotic parameters, soil quality and yield in summer mungbean}

The present study was carried out at the Pulse Research Farm, Department of Plant Breeding and Genetics, Punjab Agricultural University, Ludhiana, Punjab, India during summer 
season in 2015. Field experiment was conducted in factorial randomised block design with three replication and thirteen treatments. Seeds of summer mungbean of two varieties (SML668 and SML832) were procured from the Pulses Section, Department of Plant Breeding and Genetics, PAU, Ludhiana.

Seed rate of $15 \mathrm{Kg}$ /acre for SML 668 and 17 $\mathrm{Kg} / \mathrm{acre}$ for SML 832 was used for sowing. The summer mungbean varieties SML668 and SML832 were sown on $10^{\text {th }}$ April 2015 using 'kera' method at $22.5 \mathrm{~cm}$ row spacing, keeping a distance of about $7 \mathrm{~cm}$ between the seeds.

Mung been seeds of SML 668 and SML 832 varieties were inoculated with recommended culture of Rhizobium sp. (M1) and two native isolates of Rhizobium sp. (LSMR1, LSMR2) and PGPR (LSRB1, LSRB2 and LSRB3) as per treatment. Twenty $g$ charcoal inoculants were used per $\mathrm{kg}$ of mung bean seeds for inoculation in monoculture treatment. In coinoculation treatments, Rhizobium sp. and different PGPR were applied to mungbean seeds in ratio of 1:1. Before sowing, inoculated seeds were air dried at room temperature under shade and sown within two hours. Crop was sown on 10th April, 2015 following the recommended agronomic practice and harvested on 11 June, 2015. The observations were recorded on germination count at 10 days after sowing (DAS). Plant growth parameters viz plant height, dry weight of shoot and root, chlorophyll content of leaves, nodule number and dry weight of nodules were recorded at vegetative stage (40 DAS). Symbiotic parameters viz leghaemoglobin content of nodules, nitrate reductase activity of leaves and nodules, dehydrogenase activity (DHA) of soil were recorded at flowering stage while $\mathrm{N}$-content from soot and soil and Phosphorous (P) content of shoot and grain yield was recorded at the harvesting stage.

\section{Growth parameters}

Emergence count was obtained by recording number of emerged seedlings per meter row length from central rows of each plot after leaving two border rows on each side. For Plant height three randomly selected plants were uprooted and roots were removed from shoots and the height of shoots was measured from the base in $\mathrm{cm}$. Dry weight of shoot and root was observed by weighing the sun dried and then oven dried randomly selected uprooted plants at $60^{\circ} \mathrm{C}$ for 2 days in grams. Chlorophyll estimation was done by recording the optical density of the chlorophyll content on UV-Vis spectrophotometer using a solvent blank at $645 \mathrm{~nm}$ and $663 \mathrm{~nm}$ (Witham, 1971). Phosphorus content was estimated by digesting plant material $(0.5 \mathrm{~g})$ with $20 \mathrm{ml}$ of triacid mixture $\left(\mathrm{HNO}_{3}: \mathrm{HClO}_{4}: \mathrm{H}_{2} \mathrm{SO}_{4}\right)$ and the volume was made up to $50 \mathrm{ml}$ with distilled water; specific aliquots were used to estimate the $\mathrm{P}$ by reacting with $5 \mathrm{ml}$ of ammonium molybdate reagent in nitric acid. The volume was made up to $50 \mathrm{ml}$ and the intensity of yellow colour was estimated at $470 \mathrm{~nm}$ using spectronic 20 (Jackson, 1973). Grain yield from each plot (g/plot) was recorded and the final grain yield was expressed in $\mathrm{Kg} / \mathrm{ha}$.

\section{Symbiotic parameters}

The number of nodules per plant was recorded by taking average of nodules carefully detached from three randomly uprooted plants. The detached nodules were oven dried at $60^{\circ}$ $\mathrm{C}$ for 2 days and the dry weight of nodules per plant was recorded in $\mathrm{mg}$. Leghaemoglobin content was estimated by reading absorbance of clear nodule tissue extract with Drabkin's solution at $540 \mathrm{~nm}$ using UV-Vis spectrophotometer (Wilson and Reisenauer, 1963). Nitrate reductase activity of leaves and nodules was determined by the method of Jaworski, 1971 and the enzyme activity was expressed as $\mu \mathrm{m}$ of $\mathrm{NO}_{2} \mathrm{hr}^{-1} \mathrm{~g}^{-1}$. Total $\mathrm{N}$ 
content of shoot was determined by Kjeldahl's technique with slight modification of Mckenzie and Wallace.

\section{Soil quality parameters}

Dehydrogenase activity of soil was assayed at 40 DAS by the method of Tabatabai (1982). Total $\mathrm{N}$ content of soil was determined by Kjeldahl's technique with slight modification of Mckenzie and Wallace.

\section{Analysis of data}

Data was statistically analyzed using an analysis of variance (ANOVA) for factorial randomised block design. Further, mean separation of treatment effect was accomplished by Fisher's protected least significant difference test. All data analysis was carried out by using SAS- software.

\section{Results and Discussion}

\section{Growth parameters}

Germination is an index of dormancy and facilitate differentiation rate of germination among the varieties and treatments. Data on emergence count conclude that differences due to various treatments in both the varieties of mungbean were significant (Table 1). In co inoculation treatments germination was quite good and it varied from 90.6 to $96.0 \%$ in SML668 and 91.7 to $98.3 \%$ in SML832. Significantly higher emergence count was observed with LSMR1+LSRB3 (96.0\% and 98.3\%) followed by LSMR1+LSRB2 (94.7 and $96.7 \%$ ) as compared with Rhizobium sp. LSMR1 alone treatment (88.3 and $89.0 \%)$ in SML668 and SML832 respectively, as well as uninoculated control. Improvement in seed germination with dual inoculation might be due to release of plant growth regulators which improve morphological characters of roots (Ashrafuzzaman et al., 2009). The present study results are in harmony with the finding of Dasgupta et al., (2015) and Bent et al., (2001) who revealed that the use of PGPR with seed treatment improved seed germination; seedling emergence, seedling vigor and seedling stand over the control.

Significant difference for plant height was recorded between different dual treatments of rhizobacteria and Rhizobium sp. alone in SML 832 and SML 668 at 40 DAS. Significantly high plant height was recorded with dual inoculation treatment of LSMR1+LSRB3 $(44.7 \mathrm{~cm}$ and $46.9 \mathrm{~cm}$ ) followed by LSMR1+ LRRB1 $(44.2 \mathrm{~cm}$ and $46.3 \mathrm{~cm})$ in SML 668 and SML 832, respectively as compared to Rhizobium sp. alone treatment value and uninoculated control value. Improved plant height in dual inoculation can be attributed due to better establishment of Rhizobiumlegume symbiosis due to production of plant growth regulator by PGPR in mungbean rhizosphere (Stajkovic et al., 2011; Yadegari et al., 2010). In earlial investigation mixed inoculation of Rhizobium sp., Pseudomonas fluorescens and Bacillus megaterium significantly increased the shoot and root growth compared to uninoculated control (Anandaraj and leema, 2010). Similarly Ahmad et al., (2014) revealed that coinoculation reduced the effect of salinity on physiological parameters thus improving the photosynthetic rate which increased growth and yield of mung bean.

All the treatments and varieties differed significantly for shoot dry weight. On the basis of mean of both varieties, co-inoculation treatment LSMR1+LSRB3 showed significant increase in shoot dry weight $\left(4.75 \mathrm{~g} \mathrm{plant}^{-1}\right)$ followed by LSMR1+LSRB1(4.63 $\mathrm{g} \mathrm{plant}^{-1}$ ) as compared to Rhizobium sp. alone as well as uninoculated control. Single and combined inoculation have shown positive response to the measured growth parameters that might be attributed to changes in endogenous ethylene 
level by presence of PGPR containing ACCdeaminase on the roots of legumes (Shahroona et al., 2006; Nadeem et al., 2009; Ahmad et al., 2011). Biologically fixed $\mathrm{N}_{2}$ which might have contributed to enhancement of shoot dry weight in our study.

Significant increase in dry weight of root was observed with dual treatment of LSMR1+ LSRB3 (0.411g plant ${ }^{-1}$ and $0.604 \mathrm{~g} \mathrm{plant}^{-1}$ ) followed by LSMR1+LSRB1 (0.403 $\mathrm{g} \mathrm{plant}^{-1}$ and $0.483 \mathrm{~g} \mathrm{plant}^{-1}$ ) in SML 668 and SML832, respectively as compared to Rhizobium sp. alone as well as uninoculated control treatment. Our results are in concurrence with the findings of Verma et al., (2013) who revealed that the significant nodulation (62 and $86 \%$ ), dry weight of root (44 and 57\%) and shoot (26 and 45\%) were recorded in coinoculation of Mesorhizobium sp. and Pseudomonas aeruginosa over uninoculated control in pot and field conditions, respectively in chickpea. Inhibition of root length together with increase of root weight is a typical response to bacterial IAA production (Dobbelaere et al., 1999). Hence the increase of root weight in present work might be the result of the high levels of IAA produced by combined treatment of Rhizobium and rhizobacteria.

Chlorophyll content indicates the amount of photosynthates that are present in plants. Numeric increase in chlorophyll content was observed in LSMR1+LSRB3 (0.845 and 0.867 $\mathrm{mg} / \mathrm{g}$ fresh weight of leaves) followed by LSMR1+LSRB2 (0.802 and $0.822 \mathrm{mg} / \mathrm{g}$ fresh weight of leaves) in SML668 and SML 832 respectively. Nonsignificant difference existed among all treatments and the varieties for chlorophyll content. Results are well in accordance with Samavat et al., (2012) and Bejandi et al., (2012) who have reported that Rhizobium and Pseudomonas fluorescens treatment significantly improved leaves chlorophyll content of leaves in common bean and chickpea respectively, as compared with the control . Similarly, Rhizobium inoculation increased chlorophyll content and leaf area index by 5.43 and $6.99 \%$, respectively compared to non-inoculated plants (Namvar et al., 2013).

The data regarding phosphorus contents in shoot showed that co-inoculation significantly improved the parameter in comparison with Rhizobium sp. alone and there were significant difference among different treatment. Maximum increase in $\mathrm{P}$ content was recorded with co-inoculation of LSMR1+LSRB3 $(0.243 \%$ and $0.259 \%)$ followed by LSMR1+LSRB2 $(0.211 \%$ and $0.218 \%)$ in SML668 and SML832 respectively, as compared to Rhizobium sp. alone as well as un -inoculated control. Our results are supported by Yadav and Verma (2014) who reported that the combined inoculation of $R$. leguminosarum with $P$. aeruginosa showed significantly high $\mathrm{P}$ in grain $(58.9 \%)$ and straw (80.6\%) of chickpea over control. Similarly Stajkovic et al., (2011) reported that shoot $\mathrm{P}$ content $(0.90 \%)$ was highly affected by coinoculation of Rhizobium with Pseudomonas sp. LG strain as compared to single inoculation of Rhizobium (0.59\%). The increased concentration and uptake of $\mathrm{N}$ and $\mathrm{P}$ in plants treated with microbial inoculations suggest that a positive interaction exists between root colonization, $\mathrm{N}$ and $\mathrm{P}$ uptake, and growth promotion (Rudresh et al., 2005).

\section{Symbiotic parameters}

Nodulation is one of important parameter indicating effective legume-Rhizobia symbiosis. Significantly high number of nodules was recorded with co-inoculation in both varieties of mungbean as compared to Rhizobium sp. alone treatment at 40 DAS (Table 2). The highest number of nodules was recorded with LSMR1+LSRB3 (20.9 and 22.5) followed by LSMR1+LSRB1 (18.0 and 
20.1) in SML668 and SML832 respectively, as compared to Rhizobium sp. alone and uninoculated control treatment. Significant difference existed between both varieties for nodulation.

Significantly high nodule dry weight was recorded with LSMR1+LSRB3 (104.0 and $106.6 \mathrm{mg}$ plant $\left.^{-1}\right)$ followed by LSMR1+LSRB2 (77.9 and $81.4 \mathrm{mg} \mathrm{plant}^{-1}$ ) in SML668 and SML832 respectively, as compared to Rhizobium sp. alone treatment and uninoculated control. Difference for nodulation in both varieties was significant. Plant growth regulators (auxins) produced by PGPR play essential roles in nodule development. When co-inoculated with rhizobia resulting in improvement in symbiotic effectiveness (Sanchez et al.,2014; Yadav and Verma, 2014; Tariq et al., 2012).

Leghaemoglobin content of the nodules is taken as the index of nodule efficiency as it regulates the oxygen supply to the bacteroid and hence the nitrogenase activity. Data on leghaemoglobin content depicted significant difference in both varieties. Leghaemoglobin content of nodules produced by introduced Rhizobium isolate (LSMR1) and rhizobacteria (LSRB3) was found to be significantly high compared to Rhizobium sp. alone and uninoculated control (Table 2). The nodules formed by dual inoculation of LSMRI and LSRB3 showed maximum leghaemoglobin content $\left(2.27\right.$ and $2.31 \mathrm{mg} \mathrm{g}^{-1}$ fresh weight of nodules $^{-1}$ ) followed by LSMR2+LSRB3 (2.02 and $2.18 \mathrm{mg} \mathrm{g}^{-1}$ fresh weight of nodules) as compared to native isolate of Rhizobium sp. LSMRI (1.79 and $1.95 \mathrm{mg} \mathrm{g}^{-1}$ fresh weight of nodules $^{-1}$ ) in SML668 and SML832 respectively, as well as over un inoculated control.

Data was supported by Mishra et al., (2012) who reported that co-inoculation of Pseudomonas sp. strain PGER17 with $R$.
leguminosarum-PR1 and R. leguminosarumPR1 treated plants resulted in 17.4 and 4.76 fold increase in leghaemoglobin content over control respectively. It was reported that the leghaemoglobin has a positive correlation with $\mathrm{N}_{2}$ fixation and nitrogenase activity in nodules (Deka and Azad, 2006).

Nitrate reductase activity (NRA) provides a good estimate of the nitrogen status of plant and is correlated with growth and plant yield. Data revealed significant increase in NRA of leaves in both varieties of mungbean with single and dual treatments of different Rhizobium and PGPR. Dual treatment LSMR1+LSRB3 showed maximum increase in NRA of leaves $\left(9.98\right.$ and $11.25 \mu \mathrm{mNO}^{-2}$ $\mathrm{hr} / \mathrm{g}$ of fresh leaf tissue) followed by LSMR2+LSRB3 (10.83 and $10.23 \mu \mathrm{mNO}^{-}$ ${ }^{2} / \mathrm{hr} / \mathrm{g}$ of fresh leaf tissue) in SML668 and SML832, respectively as compared to single inoculation of Rhizobium sp. LSMR1 alone treatment. On the basis of pooled mean in both varieties the highest NRA of nodules was produced by LSMR1+LSRB1 $\left(14.63 \mu \mathrm{mNO}^{-}\right.$ $2 / \mathrm{hr} / \mathrm{g}$ of fresh nodule) followed by LSMR1+LSRB2 $\left(13.86 \mu \mathrm{mNO}^{-2} / \mathrm{hr} / \mathrm{g}\right.$ of fresh nodule) compared to Rhizobium sp. alone.

The increased NRA activity in inoculated plants could be explained by the increased efficiency of nitrogen fixation with dual inoculation of PGPR and Rhizobium sp. increased NRA directly related to increase in $\mathrm{N}$ content of shoot. Our results are in agreement with Mahmood et al., (2010) who observed increased NRA with dual inoculation of Bacillus sphaericus UPMB10 and Agrobacterium rhizogenes strains AR9402 as compared to single inoculation.and uninoculated control in banana. Similarly Ahmad et al., (2010) also reported higher NR activity in the leaves of Ammi majus L. grown with combined application of $\mathrm{S}$ and $\mathrm{N}$ when compared with $\mathrm{N}$ alone. 
Table.1 Co-inoculation effect of Rhizobium and rhizobacteria on growth parameter in summer mungbean

\begin{tabular}{|c|c|c|c|c|c|c|c|c|c|c|c|c|c|c|c|c|c|c|}
\hline \multirow[t]{2}{*}{ Treatments } & \multicolumn{3}{|c|}{$\begin{array}{c}\text { Emergence count } \\
(\%)\end{array}$} & \multicolumn{3}{|c|}{ Plant height (cm) } & \multicolumn{3}{|c|}{$\begin{array}{l}\text { Dry wt. of shoot } \\
\text { plant }^{-1}(\mathrm{~g})\end{array}$} & \multicolumn{3}{|c|}{$\begin{array}{l}\text { Dry wt. of root } \\
\text { plant }^{-1}(\mathrm{~g})\end{array}$} & \multicolumn{3}{|c|}{$\begin{array}{l}\text { Total Chlorophyll } \\
\text { content of leaves } \\
\text { (mg/g fresh weight } \\
\text { of leaves) }\end{array}$} & \multicolumn{3}{|c|}{$\begin{array}{c}\text { Total Phosphorus } \\
\text { content of shoot } \\
(\%)\end{array}$} \\
\hline & $\begin{array}{c}\text { SML } \\
668\end{array}$ & $\begin{array}{l}\text { SML } \\
832\end{array}$ & Mean & $\begin{array}{c}\text { SML } \\
668\end{array}$ & $\begin{array}{l}\text { SML } \\
832\end{array}$ & Mean & $\begin{array}{c}\text { SML } \\
668\end{array}$ & $\begin{array}{l}\text { SML } \\
832\end{array}$ & Mean & $\begin{array}{c}\text { SML } \\
668\end{array}$ & $\begin{array}{l}\text { SML } \\
832\end{array}$ & Mean & $\begin{array}{c}\text { SML } \\
668\end{array}$ & $\begin{array}{l}\text { SML } \\
832\end{array}$ & Mean & $\begin{array}{c}\text { SML } \\
668\end{array}$ & $\begin{array}{c}\text { SML } \\
832\end{array}$ & Mean \\
\hline M1 & 88.8 & 89.1 & 88.9 & 35.2 & 36.0 & 35.6 & 3.33 & 3.87 & 3.60 & 0.312 & 0.382 & 0.347 & 0.590 & 0.770 & 0.680 & 0.129 & 0.148 & 0.139 \\
\hline LSMR1 & 88.3 & 89.0 & 88.7 & 38.0 & 41.6 & 39.8 & 3.23 & 4.13 & 3.68 & 0.310 & 0.401 & 0.355 & 0.650 & 0.778 & 0.714 & 0.135 & 0.162 & 0.149 \\
\hline LSMR2 & 88.7 & 87.3 & 88.0 & $\mathbf{3 7 . 3}$ & 40.2 & 38.7 & 3.25 & 4.25 & 3.75 & 0.324 & 0.424 & 0.374 & 0.670 & 0.740 & 0.704 & 0.130 & 0.157 & 0.144 \\
\hline M1+LSRB1 & 90.8 & 91.9 & 91.3 & 40.5 & 44.0 & 42.3 & 3.54 & 4.33 & 4.27 & 0.328 & 0.446 & 0.387 & 0.686 & 0.750 & 0.718 & 0.149 & 0.177 & 0.163 \\
\hline M1+LSRB2 & 90.6 & 91.7 & 91.2 & 40.8 & 41.0 & 40.9 & 4.10 & 4.70 & 4.40 & 0.329 & 0.443 & 0.386 & 0.725 & 0.740 & 0.728 & 0.158 & 0.170 & 0.164 \\
\hline M1+LSRB3 & 90.4 & 91.7 & 91.1 & 43.2 & 44.1 & 43.7 & 4.25 & 4.33 & 4.29 & 0.365 & 0.444 & 0.404 & 0.719 & 0.731 & 0.725 & 0.168 & 0.177 & 0.172 \\
\hline LSMR1+LSRB1 & 94.7 & 93.3 & 94.0 & 44.2 & 46.3 & 45.3 & 4.05 & 5.21 & 4.63 & 0.403 & 0.483 & 0.443 & 0.782 & 0.816 & 0.799 & 0.188 & 0.178 & 0.183 \\
\hline LSMR1+LSRB2 & 94.7 & 96.7 & 95.7 & 41.0 & 45.0 & 43.0 & 4.09 & 5.16 & 4.62 & 0.392 & 0.525 & 0.458 & 0.802 & 0.822 & 0.812 & 0.211 & 0.218 & 0.215 \\
\hline LSMR1+LSRB3 & 96.0 & 98.3 & 97.2 & 44.8 & 46.9 & 45.8 & 4.22 & 5.29 & 4.75 & 0.411 & 0.604 & 0.507 & 0.845 & 0.867 & 0.856 & 0.243 & 0.259 & 0.251 \\
\hline LSMR2+LSRB1 & 90.8 & 91.7 & 91.3 & 42.3 & 45.6 & 44.0 & 4.23 & 4.37 & 4.30 & 0.372 & 0.430 & 0.401 & 0.775 & 0.803 & 0.789 & 0.109 & 0.129 & 0.119 \\
\hline LSMR2+LSRB2 & 91.0 & 92.9 & 91.9 & 41.7 & 43.1 & 42.4 & 4.44 & 4.33 & 4.38 & 0.398 & 0.450 & 0.424 & 0.742 & 0.798 & 0.770 & 0.118 & 0.201 & 0.159 \\
\hline LSMR2+LSRB3 & 92.5 & 93.0 & 92.8 & 43.2 & 46.3 & 44.8 & 4.20 & 4.39 & 4.29 & 0.395 & 0.483 & 0.439 & 0.746 & 0.772 & 0.759 & 0.203 & 0.192 & 0.198 \\
\hline Uninoculated & 87.5 & 88.4 & 87.9 & 32.1 & 35.3 & 33.7 & 2.99 & 3.28 & 3.13 & 0.297 & 0.347 & 0.322 & 0.645 & 0.659 & 0.652 & 0.103 & 0.107 & 0.105 \\
\hline Mean & 91.13 & 91.86 & & 40.3 & 42.7 & & 3.84 & 4.43 & & 0.356 & 0.451 & & 0.711 & 0.784 & & 0.157 & 0.175 & \\
\hline$C D(p \leq 0.05)$ & \multicolumn{3}{|c|}{$\begin{array}{cc}\text { T:0.91 V:0.35 } & \text { V } \\
\text { TxV: } 1.29\end{array}$} & \multicolumn{3}{|c|}{$\begin{array}{c}\text { T:0.37 V:0.14 } \\
\text { TxV:0.52 }\end{array}$} & \multicolumn{3}{|c|}{$\begin{array}{c}\text { T:0.13 V:0.51 } \\
\text { TxV: } 0.19\end{array}$} & \multicolumn{3}{|c|}{$\begin{array}{cc}\text { T: } 0.014 & \text { V: } 0.034 \\
\text { TxV: } & 0.052\end{array}$} & \multicolumn{3}{|c|}{$\begin{array}{c}\text { T:NS V:NS } \\
\text { TxV: NS }\end{array}$} & \multicolumn{3}{|c|}{$\begin{array}{c}\text { T:0.044 V:0.018 } \\
\text { TxV: NS }\end{array}$} \\
\hline
\end{tabular}


Table.2 Co-inoculation effect of Rhizobium and rhizobacteria on symbiotic parameter in summer mungbean

\begin{tabular}{|c|c|c|c|c|c|c|c|c|c|c|c|c|c|c|c|c|c|c|}
\hline \multirow[t]{3}{*}{ Treatments } & \multirow{2}{*}{\multicolumn{3}{|c|}{$\begin{array}{l}\text { No. of nodules } \\
\text { plant }^{-1}\end{array}$}} & \multirow{2}{*}{\multicolumn{3}{|c|}{$\begin{array}{l}\text { Dry wt. of nodules } \\
\text { plant }^{-1}(\mathrm{mg})\end{array}$}} & \multirow{2}{*}{\multicolumn{3}{|c|}{$\begin{array}{c}\text { Leghaemoglobin } \\
\text { content (mg/g of } \\
\text { nodules) }\end{array}$}} & \multicolumn{6}{|c|}{$\begin{array}{l}\text { Nitrate reductase activity of leaves }(\mu \mathrm{m} \\
\mathrm{NO}^{-2} / \mathrm{hr} / \mathrm{g} \text { of fresh tissue) }\end{array}$} & \multirow{2}{*}{\multicolumn{3}{|c|}{$\begin{array}{l}\text { Total } \mathbf{N} \text { content of } \\
\text { shoot }(\%)\end{array}$}} \\
\hline & & & & & & & & & & \multicolumn{3}{|c|}{ Leaves } & \multicolumn{3}{|c|}{ Nodules } & & & \\
\hline & $\begin{array}{l}\text { SML } \\
668\end{array}$ & $\begin{array}{l}\text { SML } \\
832\end{array}$ & Mean & $\begin{array}{l}\text { SML } \\
668\end{array}$ & $\begin{array}{l}\text { SML } \\
832\end{array}$ & Mean & $\begin{array}{l}\text { SML } \\
668\end{array}$ & $\begin{array}{l}\text { SML } \\
832\end{array}$ & Mean & $\begin{array}{l}\text { SML } \\
668\end{array}$ & $\begin{array}{l}\text { SML } \\
832\end{array}$ & Mean & $\begin{array}{l}\text { SML } \\
668\end{array}$ & $\begin{array}{l}\text { SML } \\
832\end{array}$ & Mean & $\begin{array}{l}\text { SML } \\
668\end{array}$ & $\begin{array}{l}\text { SML } \\
832\end{array}$ & Mean \\
\hline M1 & 15.3 & 17.8 & 16.5 & 53.5 & 56.1 & 54.8 & 1.63 & 1.59 & 1.61 & 3.39 & 3.65 & 3.52 & 5.78 & 5.27 & 5.53 & 1.25 & 1.27 & 1.26 \\
\hline LSMR1 & 14.5 & 17.8 & 16.2 & 60.9 & 65.3 & 63.1 & 1.79 & 1.95 & 1.87 & 3.98 & 4.26 & 4.11 & 8.89 & 13.75 & 11.32 & 1.29 & 1.40 & 1.35 \\
\hline LSMR2 & 15.5 & 18.3 & 16.9 & 57.0 & 62.2 & 59.6 & 1.72 & 1.76 & 1.74 & 3.43 & 3.61 & 3.52 & 8.88 & 10.15 & 9.47 & 1.28 & 1.30 & 1.30 \\
\hline M1+LSRB1 & 18.4 & 19.4 & 18.9 & 64.2 & 66.0 & 65.1 & 1.86 & 1.94 & 1.90 & 7.98 & 9.48 & 8.73 & 11.47 & 11.27 & 11.37 & 1.29 & 1.40 & 1.35 \\
\hline M1+LSRB2 & 15.8 & 18.21 & 17.0 & 68.3 & 71.2 & 69.7 & 1.97 & 2.01 & 1.99 & 6.49 & 6.59 & 6.54 & 11.92 & 13.03 & 12.47 & 1.34 & 1.35 & 1.35 \\
\hline M1+LSRB3 & 17.3 & 19.2 & 18.2 & 69.6 & 70.9 & 70.3 & 1.98 & 2.06 & 2.02 & 9.58 & 9.68 & 9.63 & 11.80 & 12.85 & 12.32 & 1.38 & 1.42 & 1.40 \\
\hline LSMR1+LSRB1 & 17.4 & 18.21 & 17.8 & 73.5 & 76.8 & 75.2 & 2.21 & 2.45 & 2.33 & 9.14 & 9.24 & 9.22 & 13.51 & 13.33 & 13.42 & 1.44 & 1.49 & 1.46 \\
\hline LSMR1+LSRB2 & 18.0 & 20.1 & 19.0 & 77.9 & 81.4 & 79.7 & 2.13 & 2.35 & 2.24 & 10.83 & 10.23 & 10.53 & 15.95 & 13.32 & 14.63 & 1.45 & 1.48 & 1.47 \\
\hline LSMR1+LSRB3 & 20.9 & 22.5 & 21.7 & 104.0 & 106.6 & 105.3 & 2.59 & 2.63 & 2.61 & 9.98 & 11.25 & 10.61 & 15.72 & 12.00 & 13.86 & 1.59 & 1.52 & 1.55 \\
\hline LSMR2+LSRB1 & 18.4 & 18.0 & 18.2 & 70.5 & 74.8 & 72.7 & 2.04 & 2.14 & 2.09 & 7.12 & 8.52 & 7.82 & 11.35 & 11.07 & 11.21 & 1.40 & 1.41 & 1.40 \\
\hline LSMR2+LSRB2 & 17.6 & 18.8 & 18.2 & 76.3 & 79.1 & 77.7 & 2.02 & 2.18 & 2.10 & 8.55 & 8.02 & 8.28 & 13.82 & 11.29 & 12.56 & 1.41 & 1.42 & 1.42 \\
\hline LSMR2+LSRB3 & 17.7 & 18.4 & 18.0 & 74.2 & 77.5 & 75.9 & 2.27 & 2.31 & 2.29 & 7.83 & 8.20 & 8.02 & 14.96 & 11.15 & 13.06 & 1.44 & 1.48 & 1.46 \\
\hline Uninoculated & 13.36 & 16.2 & 14.8 & 38.0 & 42.0 & 40.0 & 1.25 & 1.49 & 1.37 & 2.02 & 3.02 & 2.52 & 4.82 & 3.01 & 4.92 & 1.25 & 1.22 & 1.24 \\
\hline Mean & 16.9 & 18.8 & & 68.31 & 71.50 & & 1.96 & 2.06 & & 6.94 & 7.36 & & 11.45 & 11.12 & & 1.37 & 1.40 & \\
\hline$C D(p \leq 0.05)$ & $\begin{array}{l}\text { T:1.1 } \\
\text { TX V }\end{array}$ & $\begin{array}{l}\text { V:0.45 } \\
\text { NS }\end{array}$ & & $\begin{array}{l}\text { T:12. } \\
\text { T X V }\end{array}$ & $\begin{array}{l}62 \mathrm{~V}: 1 . \\
: 11.80\end{array}$ & & $\begin{array}{l}\text { T:0.2 } \\
\text { T X V }\end{array}$ & $\begin{array}{l}V: 0 . \\
0.35\end{array}$ & & $\begin{array}{l}\text { T: } 1.0 \\
\text { T X V }\end{array}$ & NS & V: NS & $\begin{array}{l}\text { T:0.92 } \\
\text { TxV: }\end{array}$ & 30 & 0.36 & $\begin{array}{l}\text { T:0.1 } \\
\text { TxV }\end{array}$ & $19^{V:}$ & 0.51 \\
\hline
\end{tabular}


Fig.1 Co-inoculation effect of Rhizobium and rhizobacteria on dehydrogenase activity in soil of summer mungbean. Each bar represents the mean of triplicate values

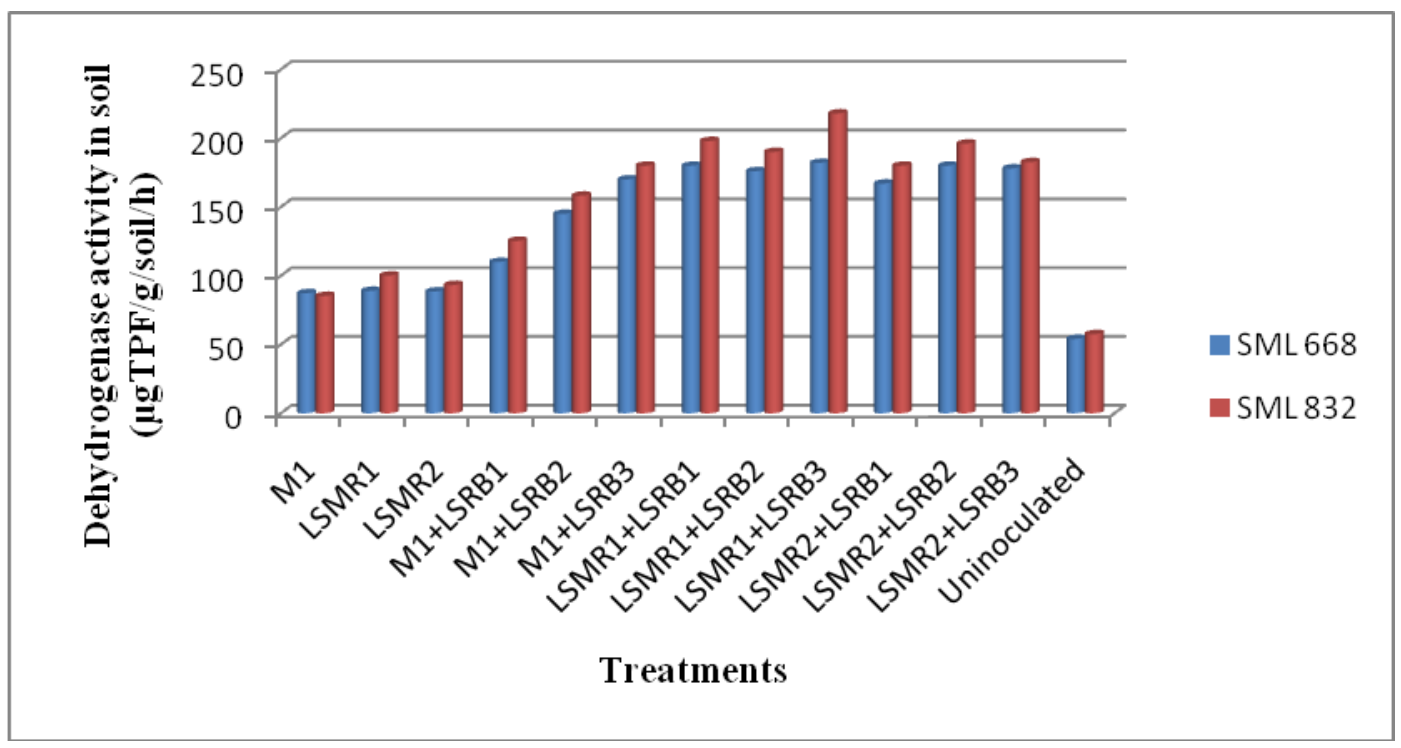

Fig.2 Co-inoculation of Rhizobium and rhizobacteria on $\mathrm{N}$ content from soil in the field of summer mungbean. Each bar represents the mean of triplicate values

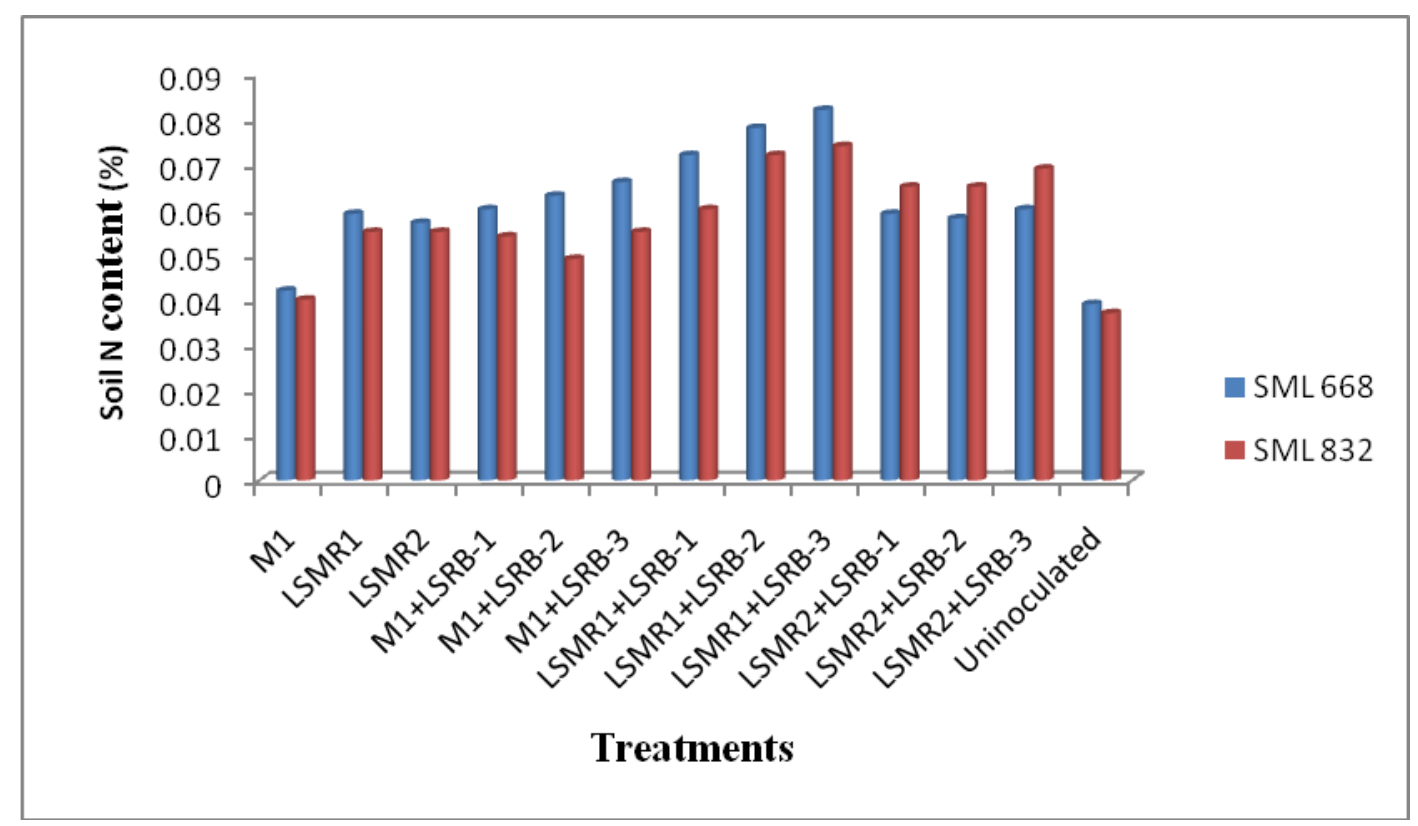


Table.3 Co-inoculation effect of Rhizobium and rhizobacteria on yield attributing traits in summer mungbean

\begin{tabular}{|l|c|c|c|c|c|c|}
\hline \multirow{2}{*}{ Treatments } & \multicolumn{3}{|c|}{ No. of pods plant } & \multicolumn{3}{|c|}{ No. of seeds pod } \\
\cline { 2 - 7 } & SML & SML 832 & Mean & SML & SML & Mean \\
\hline M1 & 668 & & & 668 & 832 & \\
\hline LSMR1 & 18.35 & 19.27 & 18.81 & 10.53 & 11.02 & 10.78 \\
\hline LSMR2 & 19.52 & 19.54 & 19.53 & 11.23 & 12.20 & 11.72 \\
\hline M1+LSRB1 & 19.25 & 19.47 & 19.36 & 10.83 & 11.66 & 11.25 \\
\hline M1+LSRB2 & 19.56 & 19.64 & 19.60 & 11.26 & 12.23 & 11.75 \\
\hline M1+LSRB3 & 19.43 & 19.80 & 19.62 & 11.27 & 12.35 & 11.81 \\
\hline LSMR1+LSRB1 & 19.53 & 19.67 & 19.60 & 11.29 & 12.46 & 11.88 \\
\hline LSMR1+LSRB2 & 20.75 & 20.97 & 20.86 & 11.86 & 12.57 & 12.22 \\
\hline LSMR1+LSRB3 & 20.8 & 21.7 & 21.25 & 13.13 & 12.73 & 12.93 \\
\hline LSMR2+LSRB1 & 19.48 & 19.84 & 19.66 & 11.6 & 12.2 & 11.63 \\
\hline LSMR2+LSRB2 & 19.02 & 19.7 & 19.36 & 11.09 & 11.83 & 11.46 \\
\hline LSMR2+LSRB3 & 19.35 & 19.81 & 19.58 & 11.24 & 11.89 & 11.57 \\
\hline Uninoculated & 17.6 & 18.20 & 17.9 & 10.24 & 11.0 & 10.97 \\
\hline Mean & 19.42 & 86.28 & & 11.31 & 12.06 & \\
\hline CD (5\%) & T:1.02 & V: 0.40 & TXV: NS & T:NS & V: NS \\
\hline
\end{tabular}


Table.4 Co-inoculation effect of Rhizobium and rhizobacteria on grain yield in summer mungbean

\begin{tabular}{|l|c|c|c|}
\hline \multirow{2}{*}{ Treatments } & \multicolumn{3}{|c|}{ grain yield(Kg/ha) } \\
\cline { 2 - 4 } & SML 668 & $\begin{array}{c}\text { SML } \\
832\end{array}$ & Mean \\
\hline M1 & 1272 & 1288 & 1280 \\
\hline LSMR1 & 1298 & 1305 & 1301 \\
\hline LSMR2 & 1287 & 1289 & 1288 \\
\hline M1+LSRB1 & 1298 & 1310 & 1304 \\
\hline M1+LSRB2 & 1318 & 1328 & 1323 \\
\hline M1+LSRB3 & 1325 & 1338 & 1332 \\
\hline LSMR1+LSRB1 & 1349 & 1359 & 1354 \\
\hline LSMR1+LSRB2 & 1358 & 1365 & 1361 \\
\hline LSMR1+LSRB3 & 1370 & 1380 & 1375 \\
\hline LSMR2+LSRB1 & 1333 & 1342 & 1337 \\
\hline LSMR2+LSRB2 & 1345 & 1356 & 1350 \\
\hline LSMR2+LSRB3 & 1355 & 1368 & 1361 \\
\hline Uninoculated & 1234 & 1244 & 1259 \\
\hline Mean & 1318.62 & 1328.62 & \\
\hline CD & T: 60 & V: NS & TxV:NS \\
\hline
\end{tabular}

Nitrogen is a vital element for plant and soil microorganism's growth and activity. Data revealed significant increase in $\mathrm{N}$ content of shoot was observed with dual treatment of Rhizobium sp. and rhizobacteria (Table 2). Significant increase of total shoot nitrogen was observed with consortium of LSMR1+LSRB3 (1.59 and 1.51\%) followed by LSMR1+LSRB2 (1.45 and $1.48 \%)$ as compared to Rhizobium sp. LSMR1 alone (1.29 and 1.40\%) in SML668 and SML832 respectively, over uninoculated control treatment. SML 832 revealed significantly high shoot $\mathrm{N}$ content as compared to SML668. Increase in N content in shoot with co-inoculation of PGPR and Rhizobium was mainly due to significant enhancement in nodulation, it resulted in higher accumulation of $\mathrm{N}$ from atmospheric $\mathrm{N}_{2}$ fixation. These results are in harmony with the finding of Stajkovic et al., (2011) reported the increase in shoot $\mathrm{N}$ content $(2.65 \%)$ with coinoculation of endophytic Bacillus sp. BX strain and Rhizobium as compared to single Rhizobium inoculation $(2.34 \%)$.

\section{Soil quality parameters}

High soil Dehydrogenase activity indicates the number of microorganisms present in the soil. Co-inoculation treatment significantly increased soil DHA with LSMR1+LSRB3 $(48.48$ and $51.34 \mu \mathrm{g} / \mathrm{TPF} / \mathrm{g} / \mathrm{soil} / \mathrm{h})$ and LSMR1+LSRB2 (43.69 and $46.47 \mu \mathrm{g} / \mathrm{TPF} / \mathrm{g} / \mathrm{soil} / \mathrm{h}$ ) in SML668 and SML832 respectively, as compared to Rhizobium sp. alone treatment (Fig.1). Difference for DHA in both varieties was significant, Similar trend was followed for N content of soil. There was a significant increase in soil $\mathrm{N}$ content was observed with co-inoculation treatment of Rhizobium and 
rhizobacteria (Fig.2). On the basis of pooled mean, significant increase was observed with consortium of LSMR1+LSRB3 (0.082 and $0.074 \%$ in SML668 and SML832, respectively) followed by LSMR1+LSRB2 (0.078 and 0.072\% in SML668 and SML832, respectively) as compared to Rhizobium sp. alone and uninoculated treatment.

Rhizospheric microorganisms influence the community structure by facilitating plant nutrient uptake and release of root exudates. Soil dehydrogenase activity provides correlative information on biological activity and microbial population in soil. Our results are in agreement with Mader et al., (2011) who showed that soil quality improved with single and dual inoculation of PGPR and arbuscular mycorrhizal fungi (AMF) with increased soil dehydrogenase activity in wheat, rice and blackgram. Similarly Meenakshi and Savalgi (2009) observed that dual treatment of Methylobacterium and $B$. japonicum increased soil dehydrogenase activity along with foliar spray in soybean. Microbial release of nutrients might have enhanced the $\mathrm{N}$ and $\mathrm{P}$ levels in soil due to increase in root hair density, more lateral roots, root surface area/ nodulation, thus more nitrogen fixation and phosphate solubilization. Our results are accordance with the work of Qureshi et al., (2011) who showed that co-inoculation resulted in higher soil $\mathrm{N}$ content as compared to control.

\section{Yield attributing traits and grain yield}

Significantly high number of pods per plant was obtained with co-inoculation of LSMR1+LSRB3 (20.8 and 21.7 pods plant $^{-1}$ ) however numeric increase was recorded with LSMR1+LSRB2 (20.75 and 20.97 pods plant $^{-1}$ ) in SML668 and SML832, respectively as compared to Rhizobium and uninoculated control treatment.
The co-inoculation treatment of Pseudomonas + Rhizobium + Azospirillum significantly increased number of pods per plant as compared with control treatment (Hosseini et al., 2014). Since the number of pod per plant is one of the factors related to grain yield, therefore any factor that increases yield also has significant affect on this trait.

Co-inoculation of Rhizobium and rhizobacteria increase the number of grain per pod (Table 3). The maximum increase in number of seeds per pod was exhibited by dual treatment of LSMR1+LSRB3 (13.13 and 12.73 grain $\left.\operatorname{pod}^{-1}\right)$ followed by LSMR1+LSRB2 (11.86 and 12.57 grain pod $^{-}$ ${ }^{1}$ ) in SML668 and SML832 respectively, as compared to Rhizobium sp. alone and uninoculated control. Non significant differences existed between varieties and treatments. These results are in harmony with findings of Hosseini et al., (2014) and Shokuh et al., (2008) who showed that Azospirillum + Rhizobium +Pseudomonas treatments had significant effect on the number of grain per pod as compared with control treatment in mungbean and soybean plant respectively . The sink capacity of plant is determine by the number of grain per pods.

Single inoculation of mungbean with different Rhizobium sp. increased the grain yield by 1.6 to $3.3 \%$ and dual inoculation increased grain yield by 3.57 to $9.21 \%$ as compared to uninoculated control (Table 4). On the basis of pooled mean of both varieties, significantly higher grain yield was recorded with consortium of LSMR1+LSRB3 (1375 Kg/ha) however numeric increase was recorded with LSMR1+LSRB2 (1361 Kg/ha) and LSMR2+LSRB3 as compared to Rhizobium sp. alone. Our results are in concurrence with Sanchez et al., (2014) who showed that the effect of Rhizobium -Pseudomonas coinoculation treatments was significantly better for grain yield compared to single Rhizobium 
inoculation. The results were further supported by Yadav and Verma (2014) who showed the combined inoculation of $R$. leguminosarum with $P$. aeruginosa has shown significantly higher increase in yield of grain (31.8\%) over control. Namvar and Sharifi (2011) also reported that Rhizobium inoculation increased grain yield per plant by about $9.04 \%$ as compared with the control. Positive results obtained in our study might be correlated to IAA production, phosphate solubilisation, ACC deaminase activity and in vitro compatibility of Rhizobium sp. with PGPR. More grains per pod recorded in our study might have leaded to more assimilates stored in grain and in turn increase in grain yield (Cheraghi et al., 2011).

In conclusion, the present research aimed to investigate native potential strains of Rhizobium and rhizobacteria ability to adapt in prevailing environmental conditions for improving productivity in summer mungbean. It was concluded that consortium of native potential isolate Rhizobium (LSMR1) and rhizobacteria (LSRB3) emerged as effective strains for improving productivity and can be developed as a single delivery system biofertilizers in summer mungbean.

\section{References}

Afzal, M. A., Murshad, N. M. M. M., Bakar, M. A., Hamid, A. and Salahuddin, A. B. M. 2008. Mungbean Cultivation in Bangladesh, Pulse Research Station, Bangladesh Agricultural Research Institute, Gazipur, Bangladesh.

Ahamd, M., Zahir, Z. A., Nadeem, S. M, Nazli, F., Jamil, M. and Jamshaid, M. U. 2014. Physiological response of mungbean to Rhizobium and Pseudomonas based biofertilizers under salinity stress. Pak J Agri Sci 51:55764.

Ahmad, M., Zahir, Z. A., Asghar, H. N. and
Asghar, M. 2011. Inducing salt tolerance in mung bean through $\mathrm{co}^{-}$ inoculation with rhizobia and plantgrowth-promoting rhizobacteria containing 1-aminocyclopropane-1carboxylate-deaminase. Can $J$ Microbiol., 57:578-89.

Ahmad, S., Fazili, I. S., Haque, R., N. and K. S. and Abdin, M. Z. 2010. Standardization and estimation of nitrate reductase activity in the leaves of Ammi majus L. (Bishops weed) in relation to sulphur deficiency and seed yield. Aust J Crop Sci., 4:515-522.

Anandaraj, B. and Leema, R. D. A. 2010. Studies on influence of bioinoculants (Pseudomonas fluorescens, Rhizobium sp. Bacillus megaterium) in green gram. J Biosci Tech., 1: 95-99.

Ashrafuzzaman, M., Farid, A. H., Razi, I. M., Hoque, M. A., Zahurul, I. M., Shahidullah, S. M. and Sariah, M. 2009. Efficiency of plant growth-promoting rhizobacteria (PGPR) for the enhancement of rice growth. Afr $J$ Biotechnol., 8:1247-1252.

Bejandi, T. K., Sharifii, R. S., Sedghi, M. and Namvar, A. 2012. Effects of plant density, Rhizobium inoculation and microelements on nodolation, chlorophyll cotent and yield of chickpea (Cicer arietinum L.). Ann Biological Res., 3:951-58.

Bent, E., Tuzun, S., Chanway, C. P. and Enebak, S. 2001. Alterations in plant growth and in root hormone levels of lodgepole pines inoculated with rhizobacteria. Can J Microbiol., 47: 793-800.

Cheraghi, S., Rafiee, M. and Khorgami, A. 2011. Effect of foliar nitrogen, planting and residue management on yield and yield components of mungbean plants in the environment Khorramabad. J Res Crop Physiol., 9:15-30.

Dasgupta, D., Ghati, A., Sarkar, A., Sengupta, 
C. and Paul, G. 2015. Application of Plant Growth Promoting Rhizobacteria (PGPR) Isolated from the Rhizosphere of Sesbania bispinosa on the Growth of Chickpea (Cicer arietinum L.) Int $J$ Curr Microbiol App Sci 4:1033-1042.

Datta, A., Singh, R. K., Kumar, S. and Kumar, S. 2015. An Effective and Beneficial Plant Growth Promoting Soil Bacterium "Rhizobium": A Review. Ann Plant Sci., 4:933-942.

Deka, A. K. and Azad, P. 2006. Screening for efficient strains of Bradyrhizobium. Indian J Pulses Res 19:79-82.

Dobbelaere, S., Croonenborghs, A., Thys, A., Vande Broek, A. \& Vanderleyden, J. 1999. Analysis and relevance of the phytostimulatory sffect of genetically modified Azospirillum brasiliense strains upon wheat inoculation. Plant Soil 212:155-164.

Gupta, G., Parihar, S. S., Ahirwar, N. K., Snehi, S. K. and Singh, V. 2015. Plant Growth Promoting Rhizobacteria (PGPR): Current and Future Prospects for Development of Sustainable Agriculture. J Microbiol Biochem Technol., 7: 196-202

Hosseini, A., Maleki, A., Fasihi, K. and Naseri, R. 2014. The Co-application of Plant Growth Promoting Rhizobacteria and Inoculation with Rhizobium Bacteria on Grain Yield and Its Components of Mungbean (Vigna radiate L.) in Ilam Province, Iran. Int $J$ Biol Food Vet Agric Eng., 8: 768-73.

Hosseini, N. M. 2008. "Agriculture and grain production", Fourth edition. Jihad Publication of Tehran University, Iran.

Jackson, W. A., Flesher, D. and Hageman, R. H. 1973. Nitrate uptake by dark-grown corn seedlings; some characteristics of apparent induction. Plant physiol., 51:120-27.

Jaworski, E. G. 1971. Nitrate reductase assay in intact plant tissues.
Biochem.Biophys.Res., 43:1274-1279.

Keatinge, J., Easdown, W., Yang, R., Chadha, M. and Shanmugasundaram, S. 2011. Overcoming chronic malnutrition in a future warming world: The keyimportance of mungbean and vegetable soybean. Euphytica., 180: 129-141.

Lazdunski, A.M., Ventre, I. and Sturgis, J .N. 2004. Regulatory circuits and communication in gram - negative bacteria. Nat. Rev. Microbiol., 2:581 592.

Mäder, P., Kaiser, F., Adholeya, A., Singh, R., Uppal, H. S., Sharma, A. K., Srivastava, R., Sahai, V., Aragno, M., Wiemken, A., Johri, B. N., Fried, P .M. 2011. Inoculation of root microorganisms for sustainable wheatrice and wheat-black gram rotations in India. Soil Biol \& Biochem., 43: 609619.

Mahmood, M., Rahman, Z. A., Saud, H. M., Shamsuddin, Z. H., Subramaniam, S. 2010. Influence of Rhizobacterial and agrobacterial inoculation on selected physiological and biochemical changes of banana cultivar, Berangan (AAA) Plantlets. J Agric Sci., 2:115-137.

Mckenzie, H. A. and Wallace, H. A. 1954. The Kjeldahl determination of Nitrogen. Au. J Chem., 17:55-79.

Meenakshi, B. C. and Savalgi, V. P. 2009. Effect of co-inoculation of methylobacterium and B. japonicum on plant growth dry matter content and enzyme activities in soybean. Karnataka J. Agric. Sci., 22:344-348.

Mishra, P. K., Bisht, S. C., Mishra, S., Selvakumar, G., Bisht, J. K., Gupta, H. S. 2012. Co-inoculation of Rhizobium leguminosarum PR1 with a cold tolerant Pseudomonas sp. improves iron acquisition, nutrient uptake and growth of field pea (Pisum sativum). J Plant Nutr., 35:243-256. 
Nadeem, S. M., Zahir, Z. A., Naveed, M. and Arshad, M. 2009. Rhizobacteria containing ACC deaminase confer salt tolerance in maize grown on salt affected soils. Can J Microbiol., 55: 1302-1309.

Namvar, A. and Sharifi, R. S. 2011. Phenological and morphological response of chickpea (Cicer arietinum L.) to symbiotic and mineral nitrogen of fertilization. Zemdirbyste Agric., pp: 121-130.

Namvar, A., Sharifi, R. S., Khandan, T. and Majid, M. J. 2013. Seed Inoculation and Inorganic Nitrogen Fertilization Effects on Some Physiological and Agronomical Traits of Chickpea (Cicer arietinum L.) in Irrigated Condition. $J$ Cent Eur Agric., 14(3): 28-40.

Pérez-Montano, F., Alías-Villegas, C., Bellogín, R. A., delCerro, P., Espuny, M. R., Jiménez-Guerrero I, LópezBaena, .F J., Ollero, F. J. and Cubo, T. 2014. Plant growth promotion in cereal and leguminous agricultural important plants: From microorganism capacities to crop production. Microbiol Res., 169:325-36.

Qureshi, M. A., Shakir, M. A., Iqbal, A., Akhtar, N. and Khan, A. 2011. Coinoculation of phosphate solubilizing bacteria and Rhizobia for improving growth and yield of mungbean (Vigna radiata L.). J Ani Plant Sci., 21:491-97.

Rudresh, D. L., Shivaprakash, M. K. and Prasad, R. D. 2005. Effect of combined application of Rhizobium, phosphate solubilizing bacterium and Trichoderma spp. on growth, nutrient uptake and yield of chickpea (Cicer aritenium L.). App Soil Ecol., 28:139-146.

Samavat, S., Mafakheri, S. and Shakouri, M. J. 2012. Promoting common bean growth and nitrogen fixation by the coinoculation of Rhizobium and Pseudomonas fluorescens isolates. Bulg
J Agric Sci., 18:387-395.

Sánchez, A. C., Gutiérrez, R. T., Santana, R., Urrutia,. A R., Fauvart, M., Michiels, J. and Vanderleyden, J. 2014. Effects of co-inoculation of native Rhizobium and Pseudomonas strains on growth parameters and yield of two contrasting Phaseolus vulgaris L. genotypes under Cuban soil conditions. Eur J Soil Biol., 62:105-12.

Shaharoona, B., Arshad, M. and Zahir, Z. A. 2006. Effect of plant growth promoting rhizobacteria containing ACC deaminase on maize (Zea mays L.) growth under axenic conditions and on nodulation in mung bean (Vigna radiata L.). Lett Appl Microbiol., 42:155-59.

Shokuh, F. A., Shoholi, R. and Ghodrati, G. 2008. Evaluate soybean response to different doses and strains of the bacterium Bradyrhizobium japonicum in the northern region of Khuzestan. Iranian J Agron., 4:81-92.

Stajkovic, O., Delic, D., Josic, D., Kuzmanovic, D., Rasulic N., Knezevic-Vukcevic, J. 2011. Improvement of common bean growth by co-inoculation with Rhizobium and plant growth promoting bacteria. Rom Biotechnol Lett., 16:5919-5926.

Tabatabai, M. A. 1982). Soil enzymes. In: Methods of soil Analysis, Part 2. (A.L. Page et al., Eds.), pp. 903-947. Academic Press, New York.

Tariq, M., Hameed, S., Yasmeen, T. and Ali, A. 2012. Rhizobial bacteria for improved nodulation and grain yield of mung bean [Vigna radiata (L.)Wilczek ]. Afr J Biotechnol., 11:15012-15019.

Valverde, A., Burgos, A., Fiscella, T., Rivas, R., Velazquez, E., Rodriguez-Barrueco, C., Cervantes, E., Chamber, M. and Igual, J. M. 2006. Deferential effects of coinoculations with Pseudomonas jessenii PS06 (a phosphate-solubilizing bacteria) and Mesorhizobium ciceri $\mathrm{C}-$ 
$2 / 2$ strains on the growth and seed yield of chickpea under greenhouse and field conditions. Plant and Soil 287:43-50.

Venkatashwarlu, B. 2008. Role of biofertilizers in organic farming: Organic farming in rain fed agriculture: Central institute for dry land agriculture, Hyderabad, 85-95.

Verma, J. P., Yadav, J. and Tiwari, K. N. 2012. Enhancement of Nodulation and Yield of Chickpea by Co-inoculation of Indigenous Mesorhizobium spp. and Plant Growth-Promoting Rhizobacteria in Eastern Uttar Pradesh. Commun Soil Sci Plant Anal., 43:605-621.

Verma, J. P., Yadav,. J, Tiwari, K. N. and Kumar, A. 2013. Effect of indigenous Mesorhizobium spp. and plant growth promoting rhizobacteria on yields and nutrients uptake of chickpea (Cicer arietinum L.) under sustainable agriculture. Ecol Eng., 51:282-286.

Wilson, D. O. and Reisenauer, H. M. 1963. Determination of leghaemoglobin in legume nodules. Anal Biochem., 6:2730.

Witham, F. H., Baldyes, D. F. and Devlin, R.
M. 1971. Chlorophyll absorption spectrum and quantitative determination. Experiment in plant physiology van Nostrand Reinhold co, New York, 55-58.

Yadav, J. and Verma, J. P. 2014. Effect of seed inoculation with indigenous Rhizobium and plant growth promoting rhizobacteria on nutrients uptake and yields of chickpea (Cicer arietinum L.) Eur J Soil Biol., 63:70-77.

Yadegari, M., Rahmani, H. A., Noormohammadi, G. and Ayneband, A. 2008. Evaluation of bean (Phaseolus vulgaris) seed inoculation with Rhizobium phaseoli and plant growthpromoting rhizobacteria on yield and yield components. Pak J Biol Sci., 11:1935-1939.

Yadegari, M., Rahmani, H. A., Noormohammadi, G. and Ayneband, A. 2010. Plant growth promoting rhizobacteria increase growth, yield and nitrogen fixation in Phaseolus vulgaris. J Plant Nutr., 33:1733-1743.

\section{How to cite this article:}

Premlata Kumari, Poonam Sharma and Sunita Sharma. 2020. Synergism of Rhizobium and Rhizobacteria on Growth, Symbiotic Parameters, Soil Quality and Grain Yield in Summer Mungbean (Vigna radiata L. Wilczek). Int.J.Curr.Microbiol.App.Sci. 9(03): 136-151. doi: https://doi.org/10.20546/ijcmas.2020.903.017 